\title{
A RAPID METHOD OF IDENTIFYING PARTICULAR BARBITURATE DERIVATIVES IN SMALL SAMPLES OF BLOOD BY PAPER CHROMATOGRAPHY
}

\author{
BY \\ J. T. WRIGHT \\ From the Medical Unit, The London Hospital
}

(RECEIVED FOR PL'BLICATION AUgUST 4, 1953)

The quantitative estimation of barbiturates in blood by ultra-violet spectrophotometry (Goldbaum, 1948 ; Walker, Fisher, and McHugh, 1948 ; Born, 1949 ; Lous, 1950 ; Wright and Johns, 1953) is of limited value unless the particular barbiturate derivative is known or can be identified. Goldbaum (1952) described an ultra-violet spectrophotometric technique by which he claimed to make such identification, but many workers with experience in this field will prefer to rely on more direct methods of qualitative analysis. For general purposes the micro-crystalline method of Turfitt (1948) is suitable if urine or gastric contents are available, though even then it is always best to confirm the identification by extraction and mixed melting point determination. Cases of barbiturate poisoning frequently occur, however, where such material is not available for analysis, or if available, does not contain adequate amounts of barbiturate, as in poisoning by short-acting derivatives. It is in these cases that a qualitative method applicable to small blood samples is of particular value. Paper chromatography seems suitable for this purpose.

Wickström and Salvesen (1952) described three satisfactory solvent systems and were able to separate 10 barbiturate derivatives by paper chromatography. Algeri and Walker (1952) were apparently the first to apply paper chromatography to blood extracts, and they explored at least 27 solvents before settling on a butanol-ammonia system which enabled them to identify 10 barbiturate derivatives. These authors used chemical methods to reveal the spots, though Algeri and Walker employed ultra-violet light to show up thiopentone. Grieg (1952) sprayed the chromatogram with alkali and demonstrated the spots by holding the paper up to a fluorescent screen illuminated by ultra-violet light.

Paper chromatography is a relatively slow process if excellent results are to be obtained, and the present method sacrifices certain refinements in the interests of speed, since a delayed report is of little use to the clinician.

\section{Principle}

Barbituric acid derivatives are selectively distributed between suitably buffered filter paper and a chloroform moving phase.

\section{Materials}

Re-distilled chloroform, Whatman No. 1 filter paper strips, stock solutions of $\mathbf{M - 2 0}$ sodium carbonate and M-20 borax for making suitable buffers, and a " hanovia chromatolite" lamp are required.

\section{Method}

Descending chromatograms are run in a glass tank measuring $25 \times 25 \times 60 \mathrm{~cm}$. fitted with a ground-glass lid and kept in a dark cupboard. The atmosphere inside the tank is kept saturated with water and chloroform vapour, but owing to the liability of chloroform to decompose, the tank is washed out frequently. Stock mixtures of $0.05 \mathrm{M}$-borax and $0.05 \mathrm{M}$-sodium carbonate are used to make up buffers of $p \mathrm{H} 10$ and $p \mathrm{H} 10.6$ as required (Clark, 1928) and the $p \mathrm{H}$ of each buffer is checked on a lithium glass electrode before use. Rectangular strips of No. 1 Whatman filter paper $15 \times 50 \mathrm{~cm}$. are then sprayed with the appropriate buffer solution, usually $p \mathrm{H} 10.6$, about $20 \mathrm{ml}$. of buffer being required to saturate this area of paper. The paper is left suspended in air by the edge which will ultimately hang lowest in the tank, and is used as soon as it feels reasonably dry. Paper which appears to have become thoroughly dry may be used provided that, after the application of the spots, it is allowed to hang in the moist atmosphere of the tank for at least an hour before the moving phase is added. Barbituric acid derivatives in $0.25 \%$ alcoholic solution are applied to the base line $2.5 \mathrm{~cm}$. apart with a capillary pipette graduated to contain $0.01 \mathrm{ml}$. Small spots are obtained by intermittently applying the pipette to filter paper under an infra-red lamp. The paper is then suspended in the tank with its upper end immersed in re-distilled chloroform. 


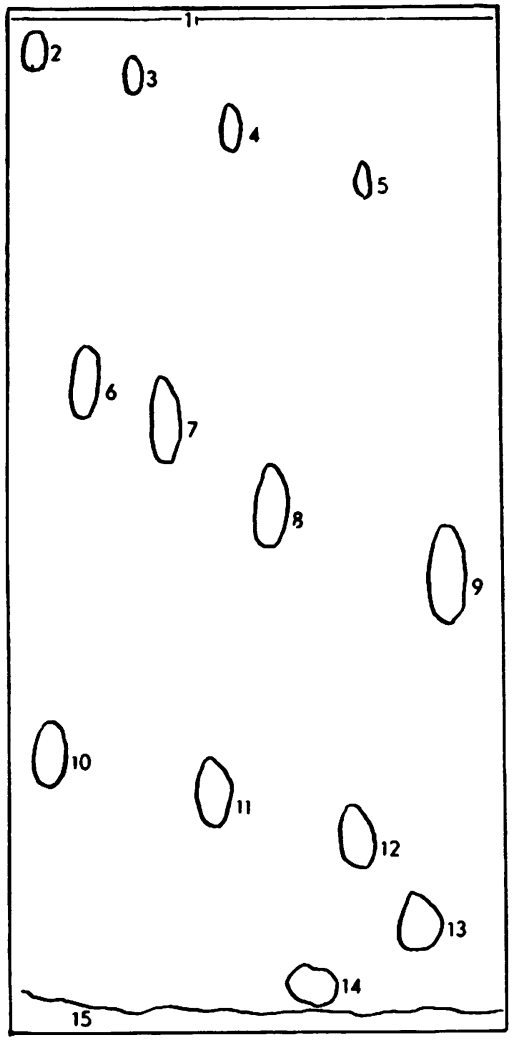

Adequate development of the chromatogram takes between four and seven hours; owing to the relatively slow progress of the solvent front as it nears the lower end of the paper, development may usually be allowed safely to continue overnight if this is more convenient. At the end of this time the paper is removed from the tank, dried in air, and is ready within five minutes to be viewed under ultra-violet light. A " hanovia chromatolite" lamp emitting maximal radiation at $253.7 \mathrm{~m} \mu$ is used, and the spots, which appear dark on a bright background, are for ordinary purposes ringed in pencil, though permanent records can be made by suitable exposure to ultraviolet light of photographic paper placed in direct contact with the chromatogram. The point of maximal density of the spot (usually its centre) is used for making measurements. Should there be any doubt regarding their identitiy as barbiturate the spots are eluted with $0.05 \%$ sodium hydroxide, buffered to $p H 10$, and the solution submitted to ultra-violet spectrophotometry. Experience showed that less material is required to give well-defined spots of slow running barbiturates such as barbital, phenobarbital, and methyl-phenyl-barbital. These are therefore applied in $0.083 \%$ solution. Well-defined spots are thus obtained with amounts of barbiturate varying from about 10 to $25 \mu \mathrm{g}$. For chromatography of blood extracts the final acid solution used for ultra-violet spectrophotometry is extracted with ether three times, the ether phase is evaporated to dryness and sufficient alcohol added to give a concentration of barbiturate estimated at about $0.25 \%$. Crude extracts of bloed made by direct shaking with ether have also been used with success, though it is difficult to obtain spots of suitable size unless the approximate quantity of baristurate present is known.

\section{Results}

Fig. 1 shows the distribution of 13 barbiturate derivatives run simultaneously on the same piefe of paper. It will be seen that in general there is a relationship between the distribution of various derivatives on the chromatogram and their relative speeds of clinical action; the slow actiong barbiturates travel slowly, medium acting barbiftrates more rapidly, and fast acting barbif̧rates most rapidly. The chromatogram thus parallels Tatum's (1939) classification of barbiturates, the only notable exception being ethyl cyclohexenyl barbiturate acid (cyclobarbitome "phanodorm") which this author classifies cas short acting and yet runs relatively slowly on 画e chromatogram. 
TABLE I

R VAlUES RELATIVE TO PENTOBARBITAL ( $p H \quad 10.6$ CHLOROFORM)

\begin{tabular}{|c|c|c|c|c|}
\hline & Mean & S.D. & Range & $\begin{array}{l}\text { No. of } \\
\text { Observations }\end{array}$ \\
\hline $\begin{array}{l}\text { Barbital } \\
\text { Phenobarb .. } \\
\text { Allyl isopropyl } \\
\text { Butobarbital .. } \\
\text { Amylobarbital } \\
\text { Quinalbarbital }\end{array}$ & $\begin{array}{l}0.12 \pm \\
0.13 \pm \\
0.61 \pm \\
0.69 \pm \\
0.93 \pm \\
1.06 \pm\end{array}$ & $\begin{array}{l}0.06 \\
0.01 \\
0.05 \\
0.04 \\
0.03 \\
0.02\end{array}$ & $\begin{array}{l}0.06-0.21 \\
0.10-0.17 \\
0.53-0.70 \\
0.63-0.75 \\
0.88-0.98 \\
1.01-1.08\end{array}$ & $\begin{array}{r}10 \\
11 \\
10 \\
13 \\
15 \\
9\end{array}$ \\
\hline
\end{tabular}

This parallelism between the chromatographic distribution and clinical action is most useful from the diagnostic standpoint, since even if a given barbiturate derivative cannot immediately be identified, its position on the paper roughly indicates its speed of action so that an estimate can be made of the significance of blood levels already obtained by spectrophotometry.

As might be expected in a chromotographic system involving the use of buffered paper with chloroform as the moving phase, in which no great pains are taken to ensure uniform temperature or humidity, absolute $\mathbf{R f}$ values are too variable to be useful in identifying particular derivatives. $R$ values relative to marker barbiturates are of more use, particularly in differentiating derivatives which lie close to the marker. Table I shows some $\mathbf{R}$ values relative to pentobarbital. It is clear that

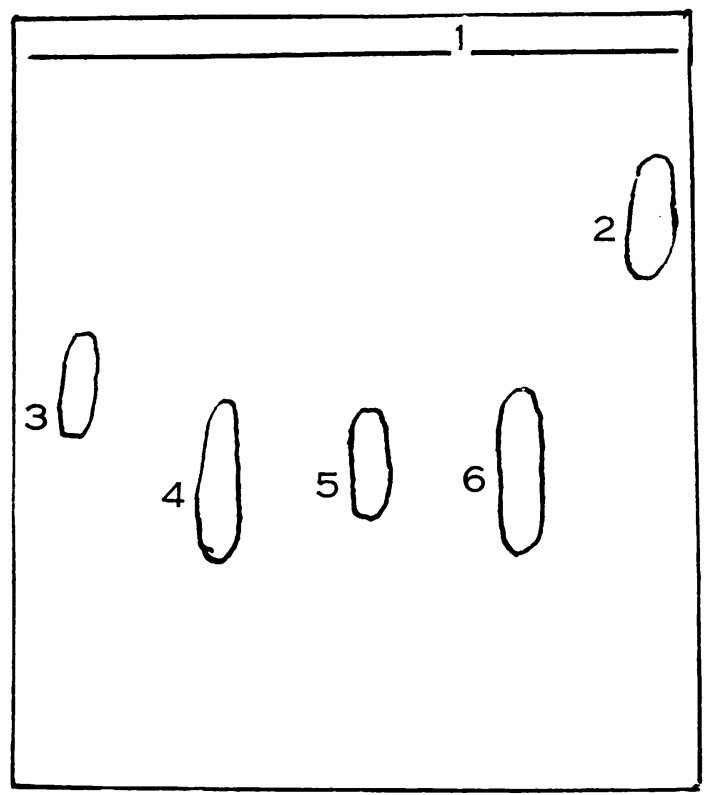

FIG. 2.-(1) Base line, (2) phenyl methyl barbituric acid, (3) diethyl barbituric acid, (4) unknown blood extract, (5) phenyl ethyl barbituric acid, (6) unknown blood extract. Conclusion.-4 and $6=$ phenyl ethyl barbituric acid. amylobarbital and quinal barbital may readily be differentiated whereas the ranges of allyl-isobutyl barbital and butobarbital overlap as also do those of barbital and phenobarbital.

In practice the identification of an unknown barbiturate is best done by running it on the same sheet of paper as known representatives of slow, medium, and quick acting derivatives. Two alcoholic solutions of markers are used here, one containing phenobarbital, butobarbital, and pentobarbital and the other barbital, allyl-isobutyl barbital, and amylobarbital.

The slower running compounds can be more widely separated by running them on paper buffered to $p \mathrm{H} 10.0$ or alternatively, using $\mathrm{N}$ butanol as solvent and paper buffered to $p \mathrm{H} 10.6$.

Figs. 2, 3, and 4 are examples of unknown drugs identified by the above technique. Fig. 4 is of particular interest in that it shows how amylobarbital and quinal-barbital may be separated in the blood of a patient who had taken a mixture of

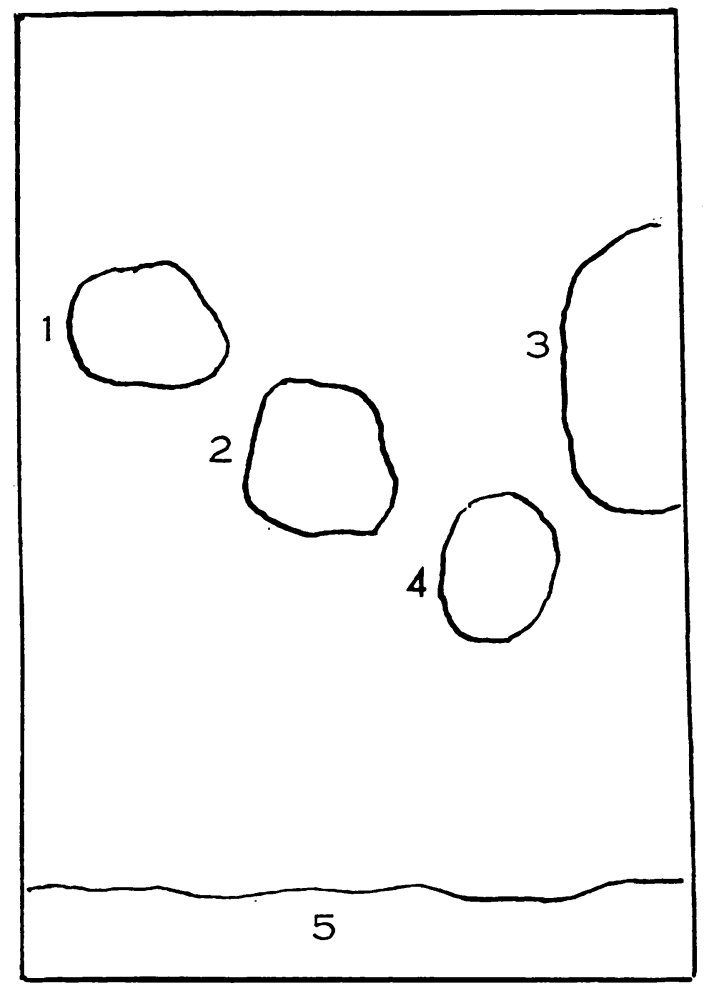

FIG. 3. - (1) Ethyl isoamyl barbituric acid, (2) ethyl (1-methylbutyl) barbituric acid, (3) unknown blood extract, (4) allyl (1-methylbutyl) barbituric acid, (5) solvent front. Conclusion.-Either the unknown blood contained both ethyl isoamyl and ethyl (1-methylbutyl) derivatives, or only one of these derivatives, the spot being too big. (Ethyl isoamyl barbituric acid was isolated from stomach contents.) 


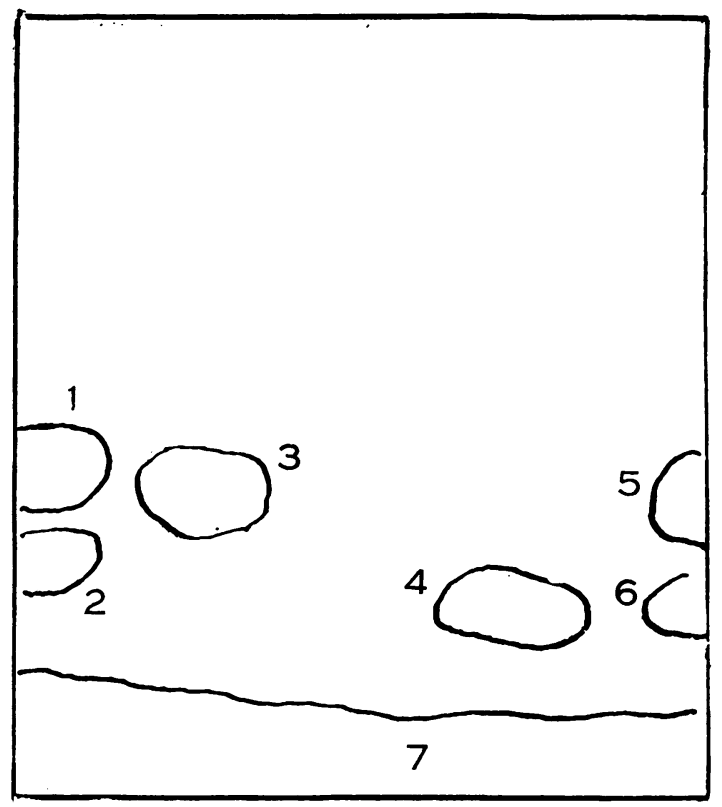

FIG. 4.-(1) and (2) Spots from extract of unknown blood, (3) ethyl isoamyl barbituric acid, (4) allyl (1-methylbutyl) barbituric acid, (5) and (6) spots from extract of stomach contents of same case as 1 and 2 , (7) solvent front. Conclusion. -1 and $5=$ ethyl isoamyl barbituric acid; 2 and $6=$ allyl (1-methylbutyl) barbituric acid.

the two ("tuinal"). Altogether the barbiturates concerned in 20 cases of poisoning have been identified by this technique and in some cases successful identification was possible on blood specimens which had been stored in a refrigerator for periods as long as 18 months. Chromatographic identification of barbiturates present in urine, gastric contents, and tissues has also been made in a few cases.

\section{Discussion}

The distribution of barbituric acid derivatives in this system presumably depends on their individual pKs and also on their solubility in chloroform. Bush (1937) gave pK values for five barbiturate derivatives as follows: phenobarbital 7.34, barbital 7.89 , amylobarbital 7.89, pentobarbital 8.04 and hexobarbital 8.23. These figures indicate a trend towards higher $\mathrm{pK}$ values in the more rapidly running compounds, as would be expected on theoretical grounds, though the fact that amylobarbital and barbital have the same pK value clearly indicates that their wide separation on the chromatogram is due to another factor. Tabern and Shelberg (1933) found that the barbiturate derivatives decreased in water solubility and increased in oil/water distribution coefficient with increase in length of the 5.5 substituted alkyl side-chains, and their data were used by Fuhrman and Field (1943) in reviewing the relationships between the physica properties and physiological actions of a number of barbiturate derivatives. Butler (1950), using mice showed that the difference in the speed of action of a slowly acting derivative (barbital) and a rapidl acting one (ortal) could be accounted for by the relatively slow appearance of the former substances in brain tissue. He postulated that the essentiat difference in physiological action between barbiturate derivatives lies in their relative ability to transe gress the brain cell membrane. Brodie (1952) has. shown that the extreme rapidity of action of thioe pental can be attributed to its high lipoid solubility rather than to chemical instability.

These researches indicate that barbiturates obe $\vec{b}$ the Meyer-Overton hypothesis, so long known to hold for volatile anaesthetics. The present obser $\overrightarrow{-}$ vations on the chromatographic distribution of $1 \mathrm{~s}$ barbituric acid derivatives suggests that theip relative solubilities in chloroform parallel theip lipoid solubilities. The position of ethyl-cyclo hexenyl barbital (cyclobarbital) is interesting, foc this substance was classified by Tatum as rapidly active. According to the chromatogram it shoul\& have a slow medium action akin to butobarbitak and this is supported by clinical experience of this drug. In contrast, however, the analogue of this substance $\mathrm{N}$ methyl cyclo-hexenyl-methy barbituric acid (" evipal ") is one of the quickes" acting barbiturates and indeed it runs almost wit $\$$ the solvent front with the system described here. $\bar{T}$

Algeri and Walker (1952) mentioned that wite their system the spots obtained in some cases from: blood samples of patients who have taken know barbiturates did not correspond with the position of the pure substance run on the same piece of paper. They interpret such differences as possible due to metabolic products of barbiturate in the blood samples. With the present method no cono vincing differences of this nature have beep obtained, the slight divergences which are some times observed being readily attributable to the size of the spot, irregularities in the texture or impregnation of the paper with buffer, or to sligh asymmetry in suspension of the paper.

\section{Summary}

A simple, relatively rapid, paper chromato graphic system is described for the separation ando identification of barbiturates in small bloo $\bar{\Phi}$ samples.

At least 13 of the common barbiturate derivative can be separated by this means and their relative distribution correlated with their speed of clinicaf action. 
I am very grateful to Dr. and Mrs. C. J. O. R. Morris for their valuable advice and to Professor Clifford Wilson for his encouragement and constructive criticism. Messrs. May \& Baker kindly supplied the 13 barbituric acid derivatives used in this work.

REFERENCES

Algeri, E. J., and Walker, J. T. (1952). Amer. J. clin. Path., 22, 37. Born, G. V. R. (1949). Biochem. J., 44, 501.

Brodie, B. B. (1952). Fed. Proc., 11, 632.

Bush, M. T. (1937). J. Pharmacol., 61, 134.

Butler, T. C. (1950). Ibid., 100, 219.
Clark, W. M. (1928). The Determination of Hydrogen Ions, 3rd ed., p. 215. Baillière, Tindall \& Cox, London.

Fuhrman, F. A., and Field, J. (1943). J. Pharmacol., 77, 392.

Goldbaum, L. R. (1948). Ibid., 94, 68.

(1952). Analyt. Chem., 24, 1604.

Grieg, A. (1952). Nature, Lond., 170, 845

Lous, P. (1950). Acta pharmacol. Kbh.,6 .227.

Tabern, D. L., and Shelberg, E. F. (1933). J. Amer. chem. Soc., 55, 328 .

Tatum, A. L. (1939). Physiol. Rev., 19, 472.

Turfitt, G. E. (1948). Quart. J. Pharm., 21, 1.

Walker, J. T., Fisher, R. S., and McHugh, J. J. (1948). Amer. J. clin. Path., 18, 451.

Wickström, A., and Salvesen, B. (1952). J. Pharm. Pharmacol., 4, 98.

Wright, J. T., and Johns, R. G. S. (1953). Journal of Clinical Pathology, 6, 78. 